\title{
Factors Influencing Health Beliefs Among People in South West, Nigeria
}

Adegoke, Adekunle Anthony (PhD)

\section{Abstract}

This paper explores the influence of personal socio demographic characteristics on the people's beliefs about the cause, treatment and prevention of disease and illness. $A$ cross-section of 338 participants were drawn from a population of literate adults in Ile-Ife using purposive sampling technique. Respondents indicated the extent of their belief on 5-point likert format scale that consisted of 16 items. The results of the analyses revealed significant influence of age, education and marital status on people's health beliefs. It was further revealed that health locus of control (especially significant others) significantly influenced health beliefs. The study concluded that an understanding of people's cultural beliefs about health issues and practices are essential if meaningful therapeutic intervention would be achieved and sustained.

\section{Background}

All human societies have patterned sets of beliefs and practices concerning their lifestyle. These patterns of thought are, to some extent, culturally determined and are to a large extent culture-bond. Various scholars have documented for African societies, a peculiar thought so characterised by what may be called a magico-religious system of thought. 
Factors Influencing Health Beliefs in South West, Nigeria.

Evans - Pritchard's (1937) study of the Azande, Temple's (1952) study of the Luba peoples, and a collection of such studies edited by Forde (1954) have amply demonstrated that African pre-industrial societies have for centuries "based their routines of living on principles of causation linking events, on the logical implications of ideas, and on an understanding of mechanical and organic process".

According to Mbiti(1969) such examination of African traditional societies immediately reveals that, "it is religion, more than anything else, which colours their understanding of the universe and their empirical participation in that universe.

Their explanations of various facets of human existence mirror the same basic religious orientation. For instance, Nduka (1974) captured the cosmological ideas which invariably encapsulate the general conception that:

Traditional African societies draw, with varying degrees of articulation, the ontological distinctions between man, nature and spirits or gods. Although the conception of a Supreme God or Spirit is also present in many cases, it must be remembered that traditional African religions have been polytheistic rather than monotheistic. Now in the cosmologies of the various African societies, it is widely believed that there is mutual involvement of nature and spirit. Thus a tree, a river, the sky, etc., may be inhabited by a spirit or spirits. Similarly, a natural phenomenon, e.g., lightning, may be associated in one way or another with a god (in this case Amadioha among Ibo, Sango among the Yoruba, etc.). It is also generally believed that gods and spirits, especially ancestral spirits, as well as other supernatural forces directly influence everyday occurrences and therefore the lives of people. Such cosmological beliefs as the foregoing provide the background for an understanding not only of traditional African 
religious and magical practices, including witchcraft and sorcery, but also of traditional African systems of thought.

African conception of illness and disease causation are often linked with this stystem of thought. Helman (1990) has noted that societies beliefs and practices relating to ill-health are central features of the culture and these are often linked to beliefs about the origin of a much wider range of misfortune (including accidents, interpersonal conflicts, natural disasters, crop failures and theft, or loss) in which ill-health is only one form. In some of these societies, the whole range of these misfortunes is blamed on supernatural forces, or on divine retribution or on the malevolence of a "witch' or "sorcerer".

It is a widespread belief in traditional African and other Non-Western societies that misfortune of which ill health is a form does not happen by chance. They are explained in terms of ancestral spirits, alien spirits, or witchcraft. (Pearce, 1989). Although there are cross cultural and ethnic differences in Africa, there is nonetheless a general belief that both physical and mental diseases originate from various external causes such as a breach of a taboo or customs, disturbances in social relations, hostile ancestral spirits, spirit possession, demoniacal possession, evil machination and intrusion of objects, evil eye, sorcery, natural causes and affliction by God or god (Baasher, 1975; Peltzer and Ebigbo, 1989).

African culture has been described as characterized by belief in supernatural forces, faith in the magic of symbols, expectations of supernatural punishment, orally preserved tribal legends and mythological concepts with emphasis on animism, full play of affective activity in daily life, complete 
Factors Influencing Health Beliefs in South West, Nigeria.

identification with the group; lowering of ego boundaries and thought processes; ancestor worship, belief in the existence of idealized good objects. There is also the tendency to regard dream life as objective reality; a simple, restricted, ill-defined and rudimentary usage of symbols, and strong religious beliefs (Lambo, 1960; Ihezue, 1989).

The links between conflict/stress, solidarity, and breakdown have also been recognized in indigenous theories of causation. Several scholars have also documented the emphasis placed on good/moral behavior and social harmony in the etiology of health in African societies (Pearce, 1989). The Hyche of Southern Tanzania believe that disruptive behaviour and the breaking of taboos are punishable and as such, misfortunes especially ill health, are expected to follow (Edgerton; 1977). In African societies, the universe is often seen as a single unit composed of the unborn, the living, dead ancestors and other deities. Beings in the spiritual realm only protect those who live according to society's norms and values. Transgression result in illness sent directly by the spirits or through the work of sorcerers and witches. This type of beliefs exists for example among the Luo in Kenya, the Amhara, in Ethiopia, the Zulu in South African and the Yoruba in Nigeria (Pearce, 1989). Several other scholars have documented similar findings corroborating this view (Simpson, 1980; Odebiyi, 1980; 1989; Odebiyi and Young; 1983; Ekong, 1982; Odebiyi and Togonu-Bickesteth, 1987; Foster and Anderson, 1978; Morley, 1978; Seijas, 1973; Valabrega, 1962).

Some attempts have been made in the classification of illness etiologies based on predominant features of African societies. Foster (1976) proposed that Non-Western disease etiologies are characterized by either personalistic or naturalistic principles. Seijas (1973) classified disease etiology into four broad categories; supernatural, Non-supernatural, 
immediate and ultimate causes. Morley and Wallis (1978) noted that such explanations of disease causation are widely found in non-western societies and have perhaps attracted most attention due to their radical departure from those prevailing in Modern Western Societies.

Helman (1990) presentation of lay theories of illness causation identified four sites; individual patient, the natural world, the social world and the supernatural world. In some cases, illness is ascribed to combinations of causes, or to interactions between these various worlds. Social and supernatural etiologies tend to be a feature of some communities in the non-industrialised world, while natural or patient-centred explanations of illness are more common in the western industrialized world, though the division is by no means absolute.

In modern Western society, lay notions of stress also place the origin of ill-health within other people; in this model, illnesses are blamed on conflicts with spouses, children, family, friends, employers or workmates. Generally, the widespread blaming of other individuals for one's own ill health is more commonly a feature of smaller and pre-industrial societies than the more Urban Western Societies.

From the supernatural world perspective, illness is ascribed to the direct actions of supernatural entities, such as gods, evil or ancestral spirits. According to Snow (1978) in a study conducted among low-income Black Americans, illness was often described as a "reminder" from God for some behavioural lapse, such as neglecting to go to church regularly, not saying one's prayers, or not thanking God for daily blessings. Illness was a "whuppin", a divine punishment for sinful behaviour. On this basis, neither home remedies nor 
Factors Influencing Health Beliefs in South West, Nigeria.

a physician were considered useful in treating the condition. A cure involves acknowledgment of sin, sorrow for having committed it and a vow to improve one's behaviour. Here, as Snow (1978) puts it; "prayer and repentance, not penicillin, cure $\sin ^{\prime \prime}$.

Generally, most cases of lay theories of illness etiology are multicausal; that is, they postulate several causes acting together. This means that individual, natural, social and supernatural causes are not mutually exclusive, but are usually linked together in a particular case. Apart from these individuals conceptual proposal in respect to the etiologies of disease and illness in African societies, a substantial number of empirical validation have been documented.

In a study conducted by Odejide and his colleagues on Traditional Healers and mental illness in 1977, it was found that $75 \%$ attributed the cause of mental illness to a curse or evil wish, $67 \%$ mentioned mysterious epidemic infection, and $47.2 \%$ mentioned different kinds of spirits. The researchers concluded that, "The healer's conception of causes of mental disorders related mostly the supernatural power". Similarly, Morakinyo (1985), in a study of somatic complaints among Yoruba reported "The ontology of motivation among Yoruba includes the belief that a person's behaviour or state of well being can be influenced by his psychosocial environment through subtle psychological, magical or mystical methods. When a person's behaviour is abnormal or does not contribute anything positive to his existence, or when his state of well being (biological, psychological and social) becomes reversed, certain people in the psychosocial environment are often (though not always) believed to be responsible".

In traditional Yoruba society, Odebiyi (1980) found that people attribute diseases and illnesses to supernatural causes. In another study, Odebiyi and Togonu-Bickersteth (1987) have discovered that diseases and misfortunes are sometimes 
associated with the sins of the parents, particularly congenital malformations for which the infants cannot be held responsible. Most studies on Yoruba health beliefs points to earlier work of Prince (1962) on the issue. His report on the Yoruba's classification of etiology of disease reveals that the disease can result from malignant influences, superhuman, drugs and medicines, heredity, contagion (not germ theory, but belief that many illnesses can be acquired from a sick person); violation of one's destiny; fate; cosmic forces; physical traumata; and psychological traumata. It was pointed that Yoruba theories of causes of illness are complex and are "part and parcel of the whole magic religious hereditary cluster of sentiment patterns which vary considerably from one group to another within the tribe." Morakinyo (1985) has noted that the elucidation of sociocultural factors like fear of sorcery and witch craft and the responses to this fear as important psycho pathogenic factor.

The belief among the people that an individual could be hurt through witchcraft, sorcery, spirits, poison, malicious, medicine has been noted by Nzewi (1989). Ebigbo (1989) also found that African believes that breaking the rules of the deity can sometimes lead to illness. The African believes that illness and health may also depend on keeping the terms of one's pre-life accord. As Prince (1975) explained, the Yorubas of Nigeria, for example believe that there is a material and an immaterial spirit world. This spirit world is the exact reflection of the real world.

These sets of phenomena, which in the west are conceived of as opposites, are understood in Africa as unities. The seen and unseen exist in a dynamic interrelationship. Past, present and future harmoniously weave one into 
Factors Influencing Health Beliefs in South West, Nigeria.

another. This way of viewing health and disease, as a matter of harmony or disharmony between an individual and a larger context, is similar to the holistic perspective being advanced currently in the developed countries. (Ebigbo, 1989). In another setting, Ihezue (1989) has noted that the clinical presentation of depressive illness among Africans has been complicated by various cultural factors, which determine its symptomatology, course, and prognosis. These cultural variables have been known to precipitate, modify, or even at times, mitigate the course and clinical pattern of illnesses.

As such, belief in external supernatural forces, human forces in the form of malicious charms and activities of other people are important in the understanding of the psychogenesis as well as the psychotherapeutic, management of certain neurotic and psychotic syndrome in African culture. As noted by Pearce (1989), the belief system and ideas of causation form an integral part of the life of any group of people. Their role in the lives of the people must be taken into account in any serious consideration of therapeutic relationship. More so, that the etiology and symptom presentation of the patients are often functions of culture.

Drawing from the definition, interpretation and etiological explanation of the psychopathological syndromes found among Igbo of south eastern Nigeria, Nzewi (1989) has suggested that an understanding of the way each culture defines and explains psychopathology and illness is of paramount importance if one is to practice meaningfully and effectively in cross cultural settings. This study is justified in the sense that the values and customs associated with ill health are part of the wider culture, and cannot really be studied in isolation from it. One cannot understand how people react to illness, death, or other misfortunes without an understanding of the type of culture they grew up in or acquired. That is, an understanding of the "lens" through 
which they perceive and interpret their health is conceived within the culture in which they exist and the belief system operating within that culture.

\section{Methodology \\ Participants}

A total of 338 respondents selected from a crosssection of literate individuals in Ile-Ife town and Obafemi Awolowo University community using purposive sampling technique participated in the study. The ages ranged from 21 to 60 years $(M=36.6 ; S . D=8.2)$ and the least of them had Secondary/Technical school education.

\section{Instrument}

All respondents received a questionnaire that consisted of two parts. The first part contained questions assessing the socio-demographic data. The second part of the questionnaire was a self-designed health belief scale (HBLS) that measures subjects' conception of illness and disease etiology, treatment and prevention.

The scale contains 16 items purposely designed to tap beliefs about health. The first 8 items focus on natural/germ theory of illness causation and management while the last 8 items address the religio-magical beliefs about illness causation and management. Items 1-4 and 9-12 measure the etiology, items 5-6 and 13-14 measures management while items 7-8 and 15-16 measures belief about preventive measures.

Respondents were to indicate the extent of their belief on a 5-point Likert format; Very small extent, small extent, to an extent, Large extent and Very large extent. The first 8 items (items 1-8) were scored in this order: very small extent -1 ; small extent -2 ; to an extent -3 ; Large extent -4 ; Very 
Factors Influencing Health Beliefs in South West, Nigeria.

large extent -5 . The last 8 items (items 9-16) were scored in reverse order that is, very small extent -5 ; small extent- 4 ; to an extent -3 ; large extent -2 ; very large extent -1 .

The scores range from $16-80$. All scores above 48 were considered as those supporting natural/germ theories of illness causation while all scores below 48 were considered as those in support of religio-magical belief of illness causation.

\section{Procedure}

Subjects were informed about the purpose of the study, which aimed at obtaining their belief about the origin/cause, treatment and prevention of illness and disease. They were instructed to indicate their level of belief by making $X$ in the appropriate box in front of each item of the Health Belief Scale. This did not pose a problem, as all the subjects were able to read and write.

\section{Results}

The first aspect of the results dealt with the descriptive findings from the health belief scale while the other part addressed the variables under examination. The information gathered on perceived etiology of disease and illness showed that one hundred and eighty-five (54.5\%) of the respondents believed that disease and illness can result from one's carelessness. One hundred and ninety-two $(57.3 \%)$ hold a strong belief that disease and illness can be as a result of dysfunction or impairment in the body system while one hundred and thirty-one (39.8\%) believed to a very large extent on natural occurrence of disease and illness without any external forces.

One hundred and ninety-six (59.4\%) hold a strong belief that disease and illness can be inherited. On religiomagical beliefs as the cause of disease and illness, one hundred and two respondents (31.3\%) believe strongly that disease and illness can be caused by evil spirits while eightyeight $(26.9 \%)$ also believed to a very large extent that disease 
and illness may result from the attack of witches, sorcerers and evildoers. In the same direction seventy-eight (23.8\%) respondents hold a strong belief that illness and disease may be as a result of retribution while one hundred and seven $(32.5 \%)$, about one-third of the total respondents believed that disease and illness might be God's punishment for sin committed.

On treatment of disease and illness, one hundred and ninety-one $(56.7 \%)$ respondents believed to a large and very large extent that all treatments must be sought from medical doctors; while Ninety-nine respondents (30.5\%) believed that there are certain diseases that western medicine cannot cure, that one may have to consult traditional healer for. Although majority of the respondents $(67.1 \%)$ believed that compliance with medical prescriptions and treatment regimen is required for healthy living, some individuals (about 29\%) still believed to a certain extent that to get disease and illness cured, one might need to appease the gods. This is corroborated further as $(35 \%)$ of the respondents indicated strong belief that seeking spiritual protection is necessary in order to escape and prevent disease and illness as well as other misfortunes.

Again, while majority of the respondents (82.9\%) believed strongly that maintaining a good hygiene is essential for staying healthy, about twenty-seven percent still have some beliefs that one may resort to using charms or talisman in order to stay healthy.

As for the influence of socio-demographic variables, it was hypothesized that neither age, education nor marital status would have significant influence on health belief. In testing these hypotheses, the study made use of t-test analysis and One-Way ANOVA. The result is presented thus: 
Factors Influencing Health Beliefs in South West, Nigeria.

Table 1: T-test Analysis of Influence of Age on_Health Beliefs

\begin{tabular}{|lcccccc|}
\hline Variable & $\mathrm{N}$ & $\mathrm{X}$ & $\mathrm{S} . \mathrm{D}$ & T-cal & T.val & $\mathrm{P}$ \\
$(21-40$ yrs $)$ & 239 & 56.86 & 10.92 & & & \\
& & & & 1.98 & 1.96 & $<0.05^{*}$ \\
$41-60$ yrs & 96 & 53.47 & 10.33 & & & \\
\hline
\end{tabular}

T-test comparison of age 21-40 yrs and 41-60 yrs adults on health beliefs revealed that age significantly influence adults health belief. The result is presented in table 1 above [t(333) $=1.98 ; \mathrm{P}<0.05]$. The result shows that there is generational difference on health beliefs. The younger generation (21-40 yrs) believed more on the impact of orthodox western medicine than the older generation of (41-60 yrs).

Adults' health beliefs were also affected by their educational status. When the scores of the various educational groups on Health Belief scale was compared using one-way analysis of variance. It was found that those who possess higher educational status (Bachelor's degrees and post graduate degrees) differ significantly in their health beliefs from those who had elementary and secondary school education. $[F(4,332)=2.45 ; P<0.05]$. This is shown in table 2 below. 
Table 2: One-way Analysis of Variance between levels of education and health beliefs.

\begin{tabular}{|c|c|c|c|c|c|c|}
\hline Source & SS & df & MS & F-ratio & F-val & $P$ \\
\hline \multirow[t]{2}{*}{ Between Groups } & 1076.45 & 4 & 269.11 & & & \\
\hline & & & & 2.45 & 2.37 & $<0.05^{*}$ \\
\hline Within Groups & 36465.84 & 332 & 109.84 & & & \\
\hline Total & 37542.29 & 336 & & & & \\
\hline
\end{tabular}

* Statistically Significant; $P<0.05$

Another significant difference was found among single and married adults when compared on health beliefs score. The result of the one-way analysis of variance as presented in Table 3 revealed that health beliefs of single adults differ significantly from that of the married adults.

Table 3: One-way Analysis of Variance between Marital Status and Health Beliefs

\begin{tabular}{|c|c|c|c|c|c|}
\hline Source & SS & df & MS & F-ratio & F-val \\
\hline \multirow{2}{*}{$\begin{array}{l}\text { Between } \\
\text { Groups }\end{array}$} & 575.43 & 1 & 575.43 & & \\
\hline & & & & 5.24 & $<0.05^{*}$ \\
\hline $\begin{array}{l}\text { Within } \\
\text { Groups }\end{array}$ & 36622.31 & 336 & 109.65 & & \\
\hline Total & 37452.64 & 337 & & & \\
\hline
\end{tabular}


Factors Influencing Health Beliefs in South West, Nigeria.

The single adults 'score' on health belief is higher than that of married adults. Thus signify that single adults believed more on the efficacy of orthodox medicine than married adults.

The analysis further revealed that health locus of control (especially, significant others) significantly influence health beliefs. See table 4 below.

Table 4: One-way Analysis of Variance between health beliefs and levels of health locus of controls.

\begin{tabular}{|llllllll||}
\hline \multicolumn{1}{|c}{ Source } & SS & df & MS & & $\begin{array}{l}\text { F- } \\
\text { ratio }\end{array}$ & $\begin{array}{l}\text { F- } \\
\text { val }\end{array}$ & p \\
Between & 1967.72 & 2 & 983.86 & & & \\
Groups & & & & & 9.22 & 3.00 & $<0.05^{*}$ \\
& & & & & & & \\
Within Groups & 34996.28 & 328 & 106.70 & & & \\
Total & 36964.00 & 330 & & & & \\
\hline
\end{tabular}

* Statistically Significant; $\mathrm{P}<0.05$

The result indicates that those classified as purely internal, significant others, and chance differ significantly on health beliefs $[F(2,328)=9.22 ; P<0.05]$. Those who believed that significant others influence their control over health believed more in orthodox/Western medicine than the internals and the purely externals.

\section{Discussion}

The pattern of results obtained on health beliefs revealed that while a high proportion of people believed in the efficacy of modern medicine perhaps because of their educational status, a sizeable number despite the influence of education still have their conception within religio-magical beliefs. This is evident in the number of people who believe 
strongly that disease and illness can be caused by evil spirits, witches and punishment for sin committed.

A number of variables were found to influence health beliefs in this study. First, the result of this study indicates a significant influence of education on health beliefs. This finding agree with that of Odebiyi and Ekong (1982) in which literacy level was significantly correlated with beliefs in the measles vaccine, thus indicating that the literacy level of the mothers is influential in determining the types of beliefs held about the vaccine.

This is also consistent with Odebiyi (1980) findings that those who had higher educational status prefer hospital treatment to traditional medicine than the non-literates who are more attached to traditional medicine. A probable explanation for these findings might be that with rising educational achievements and growth of scientific knowledge, the educated individuals are embracing the orthodox medicine more than before. This might be due to the increasing awareness and enlightenment brought about by the western education on people' ways of life which subsequently affects their belief system.

Secondly, this study revealed a significant negative influence of age on health beliefs. This trend shows that older people believed more in religio-magical conception of etiology, management and prevention of disease and illness than the younger generation. A further analysis reveals that a significant difference exist in the health beliefs of age 21-40 years group and that of age 41-60 years group; which is similar to what Odebiyi and Ekong (1983) obtained among nursing mothers in Ile-Ife. 
According to their report, mothers' belief about measles' vaccine correlate significantly with their age. Those under 40 years of age were classified as "Young" while those aged 40 and above were classified as "old". The proportion of "young" mothers who believed in the efficacy of the vaccine was significantly higher than the proportion of the "old" mothers who held the same belief. This is further corroborated by the work of Odebiyi (1980) on influence of age on the conception of disease etiology.

These findings corroborate Maclean (1971) and Mclean (1976) assertion that the young tend to believe in and use modern medical facilities more than their older counterparts. The difference between age 21-40 years group and age 41-60 years group on health beliefs were probably due in part to cohort effects and influence of western education on their belief system.

Thirdly, this study registered a significant influence of marital status on health beliefs. It was found that the single subjects believe more on the efficacy of modern medicine than married subjects. A similar finding was reported by Becker et al (1977) in a study conducted to test the applicability of Health Belief model on the prediction of dietary compliance. The age of the child and the mothers' marital status was found to influence health belief about dietary control. Their study suggests that the efficacies of medical care generally are negatively related to weight loss.

The study recorded a significant difference in the health locus of control of internal, significant others and chance groups on health beliefs. No two groups are the same on health beliefs. The level of belief of the internal group differ from that of significant others, while that of significant others also differ from that of chance group. Those who believe that their health is being controlled by significant others had the 
highest level of health belief followed by the internally controlled group and the chance group coming last.

One possible explanation of this lies on the fact that a level of belief has to be established in something before trust or control can be placed in that thing. The significant others' group seems to believe more in the efficacy of orthodox medicine than chance and internally controlled individuals both as a preventive and curative measures against disease and illness. It can thus be inferred that those who seek professional assistance for medical problems have a strong belief on the efficacy of modern medicine.

This places an average African within a mythological frame of mind, which reflects in almost every facet of their life. These findings corroborate previous works on health beliefs and disease etiology (Odebiyi 1980, Odebiyi and Ekong, 1982; Feyisetan 1992) which seems to support the supernatural causation of disease. Human beliefs about health and illness present a fascinating topic for health and allied professionals. Knowledge of disease etiology, classification, diagnosis, treatment and healing strategies differ radically from one culture to another, but holds unquestionable significance for almost everyone. (Idler, 1979). Despite medical advances leading to improved understanding of the etiology of disease, community understanding of the cause of many diseases and illnesses in Nigeria, as in many other developing countries have continued to be linked with cultural and traditional beliefs emphasising spiritual or supernatural concepts. 
Factors Influencing Health Beliefs in South West, Nigeria.

\section{Conclusion and Recommendation}

From the literature reviewed and results obtained from this study, it is evident that understanding of people's cultural health beliefs and practices are essential if meaningful therapeutic intervention would be achieved.

There is the need to include traditional health education component into any intervention programme that may be proposed from time to time. This will enlighten people about the origin, management, and prevention of disease and illness. It is also suggested that awareness be created to alter people's beliefs about disease etiology, management and prevention. For as long people define disease within the supernatural context, they might be reluctant to use scientific preventive measures which do not placate the offended spirits which may subsequently undermine whatever efforts geared toward health promotion.

\section{References}

Ebie, J.C. \& Tongue, E.J. (1988) (Eds) Handbook of the African

Training Courses_on Drug Dependence. Lau Sanne: ICAA.

Ebigbo, P.O (1989) The Mind, the Body and Society: An African Perspective. In Peltzer and Ebigbo (Eds) Clinical Psychology in Africa. Enugu working Group for African Psychology: 89-102.

Ekong, E.E. (1983) Sociology of the ibibio; A Study in Social organisation and_Change. Scholars Press, Calabar.

Evans - Pritchard, E, E (1937) Witchcraft, Oracles and Magic Among The_Azande. Oxford Clarendon Press.

Forde, D (eds) (1954) African Worlds. Oxford University Press. Foster, G.M (1976) Disease etiologies in non-western medical systems. American Anthropologist, Vol. 78, pp 775. 
Foster, G.M and Anderson, B.G. (1978) Medical Anthropology New York; Wiley, pp 53-70.

Ihezue, U.H. (1989) The Influence of Socio-Cultural factors on Symptoms

of depression Illness. In Peltzer, $\mathrm{K} \&$ Ebigbo,

P.O.(Eds)Clinical Psychology_in Africa; Enugu; Working group for African Psychology; 217-223.

Jahoda, G (1966) "Social aspirations, magic and witch-craft in

Ghana; a social psychological interpretation" pp 199 -

215. In P. Lloyd (ed) The New Elites of tropical Africa

London. Oxford University Press.

Jahoda, G. (1970) Supernatural beliefs and changing cognitive structures among Ghanaian University Students. Journal of Cross-cultural Psychology 1, 215 - 230.

Lambo T.A. (1963) African Traditional Beliefs Concepts of Health and_Medical Practice Ibadan, Nigeria, Ibadan University Press.

Lambo, T.A.(1969)Traditional African Cultures and Western Medicine

Medicine ( a critical review. In Poynter, FH (ed)

and culture London_201- 10.

Mbiti, J.S (1969) African Religions and Philosophy, p. 262. Heinemann.

Mclean, U (1978) Choices of Treatment Among the Yoruba In Walls. In Wallis, R. \& Morley, P (Eds) Culture \& Curing: Anthropological Perspectives on_Traditional Medical beliefs \& Practices. London.

Mclean, U. (1976) Some aspects of Sickness behaviour among the Yoruba. In London, J.B. (Ed) Social Anthropology and Medicine, London, Academic Press. 
Factors Influencing Health Beliefs in South West, Nigeria.

Morakinyo, O (1985) Phobic States Presenting as somatic complaints syndromes in Nigeria; Socio-Cultural factors associated with diagnosis and psychotherapy Acta Psychiatari Scandinavian 71; 356-365.

Morley, P. (1978) Culture and the Cognitive World of Traditional

Medical Beliefs; Some Preliminary Considerations. In P. Morley \& R. Wallis (Eds) Culture \& Curing London; Peter Owen Ltd.

Nduka, O.A (1974) African traditional systems of thought and their implications for Nigerian education. West African Journal of Education, Vol.XVIII, No 2.

Nzewi, E.N. (1989) Cultural factors in the classification of psychopathology in

Nigeria In Peltzer \& Ebigbo (eds) in Clinical Psychology in Africa; Enugu Pg 208 - 216.

Odebiyi, A.I. (1980) Socio-economic Status, Illness behaviour and attitudes

toward disease aetiology in Ibadan. Nigerian Behavioural Sciences_Journal3; 172-186.

Odebiyi, A.I. (1989) Food taboos in maternal and child health; the views of

traditional healers in Ile-Ife, Nigeria. Social Science and Medicine, 28; 985-996.

Odebiyi, A.I. and Ekong, S.C. (1982) Mothers' Concept of measles and attitudes toward the measles vaccine in Ile-Ife Nigeria. Journal of Epidemiology and Community Health; 36(3) 209-213.

Odebiyi, A.I. and Togonu-Bickersteth, F (1987) Concepts and Management of deafness in the Yoruba Medical system: A case study of traditional healers in Ile-Ife, Nigeria. Social Science \& Medicine; 24; 645-649.

Pearce, T.O. (1989) Social Organisation and Psychosocial 
health. In Peltzer, K. and Ebigbo. P.O. (Eds) Clinical Psychology in Africa: South of the Sahara, the Caribbean and Afro-Latin America: Enugu: Working group for African Psychology: 49-55.

Prince, R; (1962) Some Notes on Native Doctors and the Management of Mental Illness. In Lambo, T.A. (Ed) First Pan African Psychiatric_Conference, Ibadan. Government Printer, Western Region.

Prince, R (1974) Indigenous Yoruba Psychiatry. In: Kiev, A (ed) Magic, Faith and Healing: New York; The Free Press, 84-120.

Seijas (1973) An approach to the study of the medical aspects of culture Current Anthropology, December, 544-545. Simpson, G.E. (1980) Yoruba Religion and Medicine in Ibadan. Ibadan University Press.

Snow, L.F. and Johnson S.M. (1978) Folklore, food, female reproductive Cycle. Ecology, Food and Nutrition 7: 4149.

Temples, P (1952) Bantu Philosophy Presence Africaine. Young, A (1976), Some Implications of Medical Beliefs and Practices for Social Anthropology. American Anthropologist, Vol. 78, No 1, pp 5-24. 